Short notes and reviews

\title{
More than a few model species
}

\author{
Frederick R. Schram \\ Zoological Museum, University of Amsterdam, Mauritskade 57, 1092 AD Amsterdam, Netherlands
}

Review of: The Development of Animal Form, by A. Minelli. Cambridge University Press, Cambridge, UK, 2003, 323 pp., ISBN 0521808510.

"If real advances are to be made, throw away the old questions."

John Dewey (philosopher and educator)

The sub-title of this fascinating volume is "Ontogeny, Morphology, and Evolution." In its comprehensive approach, it is an example of what can result if one is willing to look at situations differently, to break away from preconceptions, and to ask some new questions that begin with the phrase, "What if ... ?" In this case, what if we throw away the adultocentric view of ontogeny, i.e., directed at the adult organism, and look at ontogeny as embryocentric, a sort of on-going Markov process directed at the next stage and not at some final cause? As Minelli cautions us in the introductory chapter, the "existence of a feedback ... does not imply the existence of a programme." There are many ways in which to look at nature, and there is value in the "multicentric view of development."

Minelli concentrates on the issue of why there are certain forms in the animal world, looking at this question from different angles. An example illustrates the point, why do certain animals have cuticular exoskeletons? No one can argue with the advantages such a skeleton might impart to an adult animal. However, long before an adult needs a skeleton upon which to anchor muscles or to provide a protective armor, a developing larva simply needs to hold its shape. The cuticle in this sense is an experiment in biomineralization to stabilize form. Certainly the issue of protection of such a tiny creature such as a larva can hardly be of consideration in an animal that could be easily consumed by a filter or detritus feeder. Minelli advocates that we stop looking for adaptationist programs to explain complete organisms. In this sense, many adult structures are merely the exaptations or non-aptations (Gould and Vrba, 198s) of embryonic features that facilitate growth and form during ontogeny.

Minelli examines in his third chapter the role of developmental genes and concludes that such genes are not so much programmed to achieve an adult body form as they are an efficient way to constrain developmental processes. In this respect, genes serve to insure some degree of order during development. Minelli reminds us to keep in view the role that epigenetic processes can also play in developing form. In this he would challenge a Dawsonian ultra-selectionist views of ontogeny: developmental genes are not the controllers of development as much as they are the selectors and chanalizers amongst an array of options.

The book abounds with examples of how preinstilled assumptions can lead one astray. For example, when one looks at the trunk of a wasp, bee, or ant, one automatically sees a 3-segment thorax before encountering the abdomen that is posterior to it, whereas careful examination of the actual form might cause one to conclude there is a 4-segment thorax with a reduced propodeum segment right after the segment bearing the third set of thoracic limbs and before the narrow "waist" demarking the insect's abdomen. Along this same line, one might 
also conclude after examining real animals that remipede crustaceans have 6 segments in their heads, rather than the "diagnostic" 5 segments all mandibulates must have.

The Development of Animal Form constantly challenges our school-taught ways of looking at anatomy. In this, it reminds me of another thought provoking book, the first volume, Promorphology, of W.N. Beklemishev's Principles of Comparative Anatomy of Invertebrates, where that author explores the "architectonics" of animal body plans before he delved into a more classic and familiar review of invertebrate organ systems. Just as in Beklemishev, Minelli sees much to be gained by looking at examples of pure morphology in terms of things like symmetry, axes, sheets of cells, tubes, and spheres. For example, what if our understanding of the polarity of the tapeworm is backward? Tradition says that tapeworms are anchored by their head and they shed mature segments at their posterior end. However, why is the scolex of a tapeworm a head? We cannot judge this by direction of locomotion - tapeworms are sessile. These animals lack any gut by which location of mouth or anus would determine polarity. However, Minelli advises us to set aside our preconceptions and examine tapeworms in light of comparative anatomy. We would then see that growth and proliferation zones in animals are typically posterior, or perceive the universal rule that female reproductive organs are located near the anterior of the body and male systems more posterior. All the inconsistencies of the classic text-book interpretation of tapeworm polarity disappear if we accept the scolex as a posterior "anchor" and not as a "head."

Of course, sometimes Minelli strays from his basic premise that we examine ontogeny with embryocentric eyes. His treatment of his merosegmentation model in chapter 9 is perhaps an instance when an adultocentric .view imposed a model to explain segment patterning and body form in myriapods. His "numbers game" leads to some interesting and controversial conclusions about what are naupliar segments and post-naupliar segments in all arthropods - even myriapods and cheliceriforms. Even though such ideas may be controversial, nonetheless the merosegmentation model provides an interesting alternative hypothesis by which we can reconsider past assumptions about arthropod form.

Minelli is aware of the dangers in this process. He cautions against distilling commonalities of anatomical plan to mere "Platonic ideals," especially when he assesses homology in chapter 10 , one of the more thought provoking sections of the book. By maintaining an open mind, Minelli encourages us to be receptive to other ways of looking at form and function during ontogeny than what we may have been taught. Why just 3 germ layers? Why not 4 ? Why not 5 ? Indeed - why not? Minelli tells us, "Homology is relative, not absolute" - a dangerous idea, indeed.

Minelli wants us to give up our biases towards finalism when we study development; ontogeny has meaning in and of itself, not just as a process towards adulthood. He wants us to consider generic rather than genetic causes of animal form, to see genes as chanalizers and stabilizers. He warns us to think small, think short term, and think broadly. It is a refreshing view of life.

\section{References}

Beklemishev WN. 1969. Principles of Comparative Anatomy of Invertebrates. University of Chicago Press, Chicago.

Gould SJ, Vrba E. 1982. Exaptation - a missing term in the science of form. Paleobiol. 8: 4-15.

Received: 2 July 2004 